\title{
(t)
}

\section{DO “DESENVOLVIMENTO SUSTENTÁVEL" À ECONOMIA VERDE: AS FALSAS PROPOSTAS DO CAPITAL EM ÉPOCA DE CRISE}

The "sustainable development" for the green economy: the false proposals of capital in times of crisis

\section{Rachel Santos Zacarias'}

\section{RESUMO}

A partir dos referenciais teórico-metodológicos de investigação da teoria social marxiana, este artigo tem como objetivo apresentar os limites das propostas que vêm sendo construídas no âmbito dos órgãos oficiais com relação ao enfrentamento da destruição ambiental produzida pelo modelo de produção capitalista. Procura-se demonstrar que essas propostas, utilizadas como referência para se pensar o tipo de desenvolvimento a ser adotado nos países, escondem, atrás do chamado "desenvolvimento sustentável" e da "economia verde", o compromisso com a conservação da ordem econômico-social vigente e não com sua mudança.

\section{PALAVRAS-CHAVE}

Crise do capital. Destruição ambiental. Desenvolvimento sustentável. Economia verde.

\footnotetext{
1 Professora colaboradora do Grupo de Educação de Ambiental da UFJF. Profes ᄀsora do Instituto Vianna Júnior - Juiz de Fora (MG). E-mail: <rachel.zacarias@gmail.com>.
} 


\section{ABSTRACT}

From the theoretical and methodological research of Marxist social theory, this article aims to show the limits of the proposals that have been built as part of official agencies in relation to coping with environmental destruction produced by the model of capitalist production. It seeks to demonstrate that these proposals used as a reference for thinking about the kind of development to be adopted in countries hide behind the so-called "sustainable development", and "green economy" commitment to the conservation of existing social economic order and not with his change.

\section{KEYWORDS}

Crisis of capital. Environmental destruction. Sustainable development. Green economy.

\section{INTRODUÇÃO}

A situação de deterioração ambiental e a precariedade em que se encontram os sistemas naturais que sustentam a vida no planeta vêm sendo amplamente reconhecidas por diversos setores representativos da sociedade contemporânea, principalmente a partir da década de 60 do século XX. A partir desse reconhecimento do esgotamento de um modelo que acaba com a estabilidade ecológica, social e política, passam a ser construídas diversas propostas.

De um lado, estrutura-se um pensamento que se opõe à ideologia do capital, formado por pensadores críticos ao modelo de produção capitalista, por movimentos sociais, fora da lógica do mercado. Para esse pensamento, as condições que levam à degradação ambiental têm causas econômicas e políticas e sua gênese está ligada às relações sociais que se firmam entre os seres humanos a partir da maneira como se distribuem os meios de produção. Essa distribuição dos meios de produção, segundo Acselrad (2001), determina um ingresso diferente ao meio 
ambiente, graus de interferências e de decisão diferentes sobre o uso do meio ambiente e leis que governam o ritmo, a forma e o tipo de recursos a se utilizar. A partir dessa concepção, não é possível entender os problemas de depredação do meio ambiente sem levar em conta o modo de produção capitalista da sociedade contemporânea.

De outro lado, estrutura-se uma corrente de pensamento atualmente hegemônica, defendida por representantes ligados às instituições financeiras multilaterais e às grandes corporações internacionais. Nessa concepção, defende-se que o cerne dos problemas ambientais está ligado ao desperdício de matéria e energia, portanto, um limitador para a expansão da economia e para o crescimento do mercado. Além disso, defende ações da chamada modernização ecológica, destinadas essencialmente a promover ganhos de eficiência e ativar mercados. Age principalmente no âmbito da lógica econômica, conferindo ao mercado a capacidade institucional de resolver a degradação ambiental, economizando o meio ambiente e abrindo mercados para novas tecnologias ditas limpas. É a partir desses pressupostos que essa corrente vem construindo as propostas de desenvolvimento sustentável e economia verdes, como alternativas para enfrentamento da atual crise do capital e ambiental em curso.

É a partir desse contexto que este artigo visa apresentar os limites das propostas que vêm sendo construídas no âmbito dos órgãos oficiais com relação ao enfrentamento da destruição ambiental produzida pelo modelo de produção capitalista. Procura-se demonstrar que essas propostas, utilizadas como referência para se pensar o tipo de desenvolvimento a ser adotado nos países, escondem, atrás do chamado desenvolvimento sustentável e da economia verde, o compromisso com a conservação da ordem econômico-social vigente e não com sua mudança. 


\section{CRISE DO CAPITAL E A DESTRUIÇÃO AMBIENTAL: UMA ANÁLISE CRÍTICA}

A partir de 1970, uma nova fase passa a ser vivida pelo sistema do capital, denominada por Mészáros (2006) de crise estrutural do capital. Para o referido autor, desde essa época, que foi marcada por um depressed continuum, o modo de produção capitalista, depois de viver uma longa fase determinada por períodos cíclicos de expansão e crise, passa a exibir características de uma nova forma de crise. Nesta, não acontecem os espaços entre expansão e recessão definidos pelas contradições no processo de acumulação de riqueza e de produção-consumo, mas há a eclosão de precipitaçõos cada vez mais frequentes e contínuas. De acordo com Mészáros (2011; 2002), a crise afeta pela primeira vez na história a totalidade da humanidade e todos os pontos os pontos do planeta, mostrando-se longeva e duradoura, sistêmica e estrutural, reduzindo a margem de alternativas factíveis do capital em sua busca de sustentabilidade no processo de acumulação de riqueza. Isso se explicita por meio de sua tripla destrutividade: (1) ampliação de guerras cujo movimento se inicia no imperialismo monopolista do século XIX; (2) intensificação do uso dos bens naturais acima da capacidade de suporte, degradação dos ecossistemas e extinção em massa da diversidade; (3) aumento da produção destrutiva, pautada na obsolescência simbólica e material das mercadorias.

Outra diferença entre a crise cíclica e a crise estrutural está relacionada ao deslocamento das contradições, o que só é possível enquanto a crise for parcial, relativa e interiormente manejável dentro do sistema, demandando apenas mudanças - mesmo que importantes - no interior do próprio sistema relativamente autônomo (ajustes fiscais, reforma do estado, garantia de direitos etc.). Esse raciocínio também é válido quando se trata de limites. Numa crise estrutural, os limites não estão relacionados aos limites imediatos possíveis de serem enfrentados por meio desses deslocamentos, mas aos limites últimos de uma estrutura global, que implicam em sua inviabilidade no processo de reprodução social e na garantia da sobrevivência.

Portanto, em relação à natureza da crise estrutural, suas características definidoras são as seguintes: i) o seu caráter é universal. 
Isso significa que a crise não afeta apenas este ou aquele ramo particular de produção, ou este e não aquele tipo de trabalho; ii) tem um alcance global, atingindo todos os países, e não um conjunto particular de países, como foram as crises cíclicas; iii) sua escala de tempo é contínua e permanente, ao invés de limitada e cíclica como as crises anteriores; iv) seu modo de evolução é rastejante, em contraste com as erupções e os colapsos espetaculares e dramáticos no passado.

Esse tipo de posicionamento inverte uma máxima ambientalista. A crise não é determinantemente ambiental e sim do sistema do capital, no qual a questão ambiental é uma de suas manifestações mais evidentes. É essa crise estrutural do capital, cujas forças potencialmente destruidoras estavam inscritas nos fundamentos do capitalismo, que vem colocando em risco as duas fontes de produção de valor e de toda a riqueza produzida: a capacidade de trabalho e a natureza.

Para analisar as questões relativas às interações metabólicas homem e natureza, Marx (1983, p. 149) destaca o trabalho como elemento central de mediação. Para o autor, "[...] o trabalho é um processo entre o homem e a natureza, um processo em que o homem, através de sua própria ação, media, regula e controla o seu metabolismo com a natureza". Sendo assim, é através do trabalho que o homem encara os materiais da natureza como uma força da natureza. Ele põe em movimento as forças naturais pertencentes ao seu próprio corpo, a fim de se apropriar dos materiais da natureza de uma forma adaptada às suas próprias necessidades. Através desse movimento, ele atua sobre a natureza externa e a modifica, e com isso, simultaneamente, altera sua própria natureza.

O trabalho é a condição universal da interação metabólica entre o homem e a natureza, a perpétua condição da existência humana imposta pela natureza. Ademais, para Marx, a humanidade e a natureza estão inter-relacionadas. Para ele, ao entrar diretamente na história do homem através da produção, a natureza é como se fosse uma extensão do corpo humano.

Para descrever a relação do homem com a natureza, Marx utilizou o conceito de metabolismo. A palavra implica diretamente, nos seus elementos oriundos das ciências naturais, incorporados pelo autor 
alemão, uma noção de troca e transformações orgânicas da matéria. Esse conceito foi empregado por Marx para se referir à real interação metabólica entre a natureza e a sociedade através do trabalho humano (contexto em que o termo era normalmente usado nas suas obras) e, num sentido mais amplo, para descrever o conjunto complexo, dinâmico e interdependente das necessidades e relações geradas e constantemente reproduzidas de forma alienada no capitalismo. Além disso, refere-se também à questão da liberdade humana suscitada por Marx - tudo podendo ser visto como ligado ao modo como o metabolismo humano com a natureza era expresso através da organização concreta do trabalho humano. O conceito de metabolismo assumia, assim, tanto um significado ecológico quanto um significado social mais amplo. Porém, na maturidade, o conceito posterior de metabolismo de Marx permitiu-lhe expressar essa relação fundamental de forma mais científica e sólida, retratando a troca complexa, dinâmica, entre os seres humanos e a natureza, decorrente do trabalho humano (FOSTER, 2005).

O conceito de metabolismo, com as suas noções subordinadas de ação regulatória e trocas materiais socialmente mediadas e historicamente determinadas, permitiu que Marx expressasse a dialética com a/na natureza como uma relação que abrangia tanto as condições impostas pela natureza quanto a capacidade dos seres humanos de afetar esse processo. Além disso, possibilitou um modo concreto de expressar a noção de alienação da natureza enquanto momento da alienação do trabalho:

Não é a unidade da humanidade viva e ativa com as condições naturais inorgânicas, da sua troca metabólica com a natureza, e daí a sua apropriação da natureza, que requer explicação, ou é o resultado de um processo histórico, mas a separação entre estas condições inorgânicas da existência humana e essa existência ativa, uma separação que é integralmente postulada na relação trabalho assalariado com o capital (MARX, apud FOSTER, 2005, p. 223).

Essa alienação que acontece sob o domínio do capital se dá tanto em relação ao trabalho quanto à natureza, pois são fontes materiais do processo de produção social fundado sob a apropriação privada e a expropriação (MÉSZÁROS, 2006). 


\begin{abstract}
O trabalho não é a fonte de toda a riqueza. A natureza é a fonte dos valores de uso (que são os que verdadeiramente integram a riqueza material) nem mais nem menos que o trabalho, que não é mais que a manifestação de uma força natural, da força de trabalho do homem (MARX, 1981, p. 209).
\end{abstract}

Ao entender o processo de alienação em sua totalidade na unidade dialética social-natural, Marx coloca por terra a crítica de algumas correntes do movimento ambientalista que o acusam de negligenciar o valor da natureza no processo de produção. Mais do que isso, para o pensador alemão, a distinção dialética do ser humano na natureza não significa duas essências, mas uma única (que é a própria natureza), a partir da qual nos constituímos como humanos na atividade social e nos modos de produção. Ou seja, a relação alienada e coisificada é um produto histórico das relações do capital e não algo essencializado ou condição inexorável da existência humana (LUKÁCS, 2010).

Para capturar a alienação material dos seres humanos dentro da sociedade capitalista e das condições naturais que formaram a base da sua existência, Marx empregou o conceito de falha ou ruptura na relação metabólica. Essa falha metabólica acontece em decorrência do rompimento do metabolismo complexo entre sociedade e natureza no modo de produção capitalista, no qual ocorre a quebra da capacidade de regeneração, recuperação e de suporte material e energético aos processos humanos. Para Marx (2011), essa falha é irreparável, porém não irreversível. É irreparável na medida em que, uma vez produzida, não se encontra força material para repará-la, a não ser que ocorra uma mudança qualitativa na relação entre sociedade e natureza.

A partir dessas reflexões, pode-se dizer que a concepção marxiana traz uma contribuição crítica e revolucionária para entender as relações sociedade-natureza (LOUREIRO, 2006). Para além das explicações recorrentes do ambientalismo - que dizem da finitude dos recursos naturais decorrente da pressão quantitativa de pessoas pensada abstratamente -, Marx (2011) demonstra que a degradação ambiental tem as suas causas determinadas pelo modo de produção e por demais questões políticas e culturais ligadas a um processo de dupla exploração (o trabalho e a natureza). Consequentemente, ele defende que um novo metabolismo só será 
possível a partir da livre associação entre produtores, num processo no qual haverá um controle comunal sobre as trocas materiais com a natureza, na esfera da produção material, e a total abolição da propriedade privada.

Depois de mais de cento e cinquenta anos das contribuições de Marx para se pensar ontologicamente a sociedade e a natureza, a lógica destrutiva do processo de produção e acumulação do capital se aprofundou. Em relação à natureza, a partir da década de 1970, a situação de precariedade encontrada nos sistemas naturais que sustentam a vida no planeta passa a ser reconhecida oficialmente por diversos setores da sociedade global. A partir desse reconhecimento surgem diversas reações sobre as determinações da chamada crise ambiental, assim como a busca de alternativas para o enfrentamento desses problemas.

Com esses referenciais, este artigo parte da tese de que as condições que levam à degradação ambiental são determinadas pelo modo de produção em um complexo de relações que envolvem tecnologia, ciência e instituições políticas. Portanto, a chamada crise ambiental deve-se a um conjunto de variáveis interconexas, dadas em bases sociais, econômicas, culturais e políticas, estruturalmente desiguais, que conformam a sociedade capitalista. Essa perspectiva, formada por pensadores críticos no que tange ao modelo de produção capitalista e por atores vinculados aos movimentos sociais, fora da lógica do mercado, está longe de ser politicamente homogênea, mas a maioria dos seus representantes compartilha alguns princípios vitais. Pode-se destacar, entre eles, a utilização do referencial teórico-metodológico histórico dialético como método de análise, a vinculação entre a crise ambiental e o modelo de produção capitalista e, por fim, a associação entre a transformação social com a transformação das relações humanas com a natureza.

Diferentemente dessa concepção crítica, a concepção hegemônica compreende que o cerne da crise ambiental está ligado às seguintes causas: ao desperdício de matéria e energia, aos limites físicos e naturais dos recursos naturais e aos altos padrões de produção e consumo. Quanto às alternativas, estas se restringem aos processos de produção, tecnologia e eficiência energética, levando a uma despolitização da questão ambiental. Essa concep- 
ção, que vem sendo utilizada para se pensar o tipo de desenvolvimento a ser adotado nos países, esconde, atrás do chamado desenvolvimento sustentável e da economia verde, o compromisso com a conservação da ordem econômico-social vigente e não com sua transformação. A seguir serão discutidos os principais pressupostos dessa concepção.

\section{O “DESENVOLVIMENTO SUSTENTÁVEL" E A ECONOMIA VERDE: O COMPROMISSO COM A CONSERVAÇÃO DA ORDEM ECONÔMI- CO-SOCIAL VIGENTE E NÃO COM SUA MUDANÇA}

A partir da década de 1970, a situação de precariedade encontrada nos sistemas naturais que sustentam a vida no planeta passa a ser reconhecida oficialmente por diversos setores da sociedade global. O pensamento hegemônico defendido por representantes ligados aos órgãos oficiais, às instituições financeiras multilaterais, às grandes corporações vem ao longo dos últimos 40 anos criando conceitos, como o desenvolvimento sustentável, e organizando documentos, como a Agenda XXI, que são utilizados como referência para implementar o desenvolvimento, agora considerado sustentável, a ser adotado nos países e no Brasil.

O conceito de Desenvolvimento Sustentável (DS) foi estruturado a partir do relatório produzido pela Comissão Mundial sobre o Meio Ambiente e Desenvolvimento (CMMAD) da ONU, denominado $O$ nosso futuro Comum. Esse relatório apresenta as condições ambientais do planeta e suas relações com o modo de desenvolvimento adotado pelos países. Esse documento oficial sistematiza o conceito de (DS), consagrado após a Conferência do Rio - 1992, como “[...] aquele que atende às necessidades do presente sem comprometer as gerações futuras de atenderem às próprias necessidades". Defende-se que o Desenvolvimento sustentável é um processo de transformação no qual a exploração dos recursos, a direção dos investimentos, a orientação do desenvolvimento tecnológico e a mudança institucional se harmonizam e reforçam o potencial presente e futuro para que possam atender às necessidades e aspirações humanas (PINTO, 2002). 
Um dos pressupostos utilizados para se pensar o desenvolvimento sustentável está relacionado à crítica ao excesso da população e seu impacto no meio ambiente. À pressão demográfica são atribuídos todos os males do mundo contemporâneo - desertificação, fome, esgotamento de recursos, degradação do ambiente, entre outros.

O debate sobre os aspectos demográficos e a pressão sobre os recursos naturais foi inaugurado por Thomas Robert Malthus (1766-1834). Malthus escreveu o primeiro ensaio anônimo intitulado Ensaio sobre o princípio da população e seus efeitos sobre o futuro aperfeiçoamento da sociedade, com observações sobre as especulações de Mr. Godwin, M. Condorcet e outros autores. No seu ensaio, Malthus sustentava a visão de que o princípio mais importante que norteava a sociedade humana era o "[...] princípio da população [...]”. Para Malthus havia uma constante desproporção entre a sobrecarga populacional - que, na ausência de limites, crescia naturalmente em taxa geométrica (1, $2,4,8,16$, e assim por diante) - e o crescimento mais limitado dos meios de subsistência, que tendia apenas a um crescimento aritmético (1, 2, 3, 4, 5, e assim por diante). A segunda questão está relacionada à necessidade, diante dessas circunstâncias, de se chegar a um equilíbrio entre o crescimento populacional e o crescimento dos meios de subsistência. Para resolver essa questão, Malthus propôs a adoção de abstinência sexual (nas classes menos favorecidas) e a redução dos programas assistencialistas governamentais e privados (MALTHUS, 1982).

Com o passar do tempo, viu-se que as previsões de Malthus eram mais apocalípticas que a própria realidade e, já naquela época, elas sofreram várias críticas. Em relação à coerência dos argumentos de Malthus, no que diz respeito à defesa do crescimento geométrico da população, esse ponto já havia recebido comprovação empírica antes de Malthus escrever o seu ensaio; mas, em relação ao crescimento aritmético dos alimentos, a sua alegação ficava inteiramente confinada.

Apesar da fragilidade dos argumentos da teoria de Malthus e de suas projeções não se confirmarem, sua teoria conseguiu subsistir dois séculos, sendo comum a menção de suas propostas 
quando se debatem as questões relativas ao desenvolvimento, subdesenvolvimento, demografia e meio ambiente. Segundo Rodrigues (2011), na década de 1970 a teoria malthusiana foi revisitada ao se iniciarem as discussões sobre crescimento populacional no terceiro mundo. Os neomalthusianos compreendiam o excedente populacional como um entrave ao desenvolvimento, argumentando que boa parte dessa população seria formada por pessoas improdutivas, como jovens e crianças, e que os recursos destinados a sustentá-las poderiam ser investidos na produção, o que contribuiria para o progresso econômico dos países. Nesse período, houve uma preocupação com o controle de natalidade nas nações subdesenvolvidas; o Banco Mundial e o Fundo Monetário Mundial começaram a exigir Políticas de Planejamento Familiar. Essa preocupação se amparava na ideia de que a escassez de recursos e a superpopulação impedem o desenvolvimento da humanidade.

Ainda na década de 1970, a menção à teoria malthusiana foi retomada pelo documento Limites do Crescimento, elaborado pelo Clube de Romá2. Esse documento, que serviu de base para a Primeira Conferência sobre Meio Ambiente Humano em 1972, defende a tese do crescimento zero, advogando a necessidade do congelamento do aumento da população e do crescimento do capital industrial.

A preocupação em conter o crescimento da população devido à finitude de recursos naturais está também presente no relatório da Comissão sobre Meio Ambiente e Desenvolvimento. Ao discutir População e recursos humanos essa apreensão fica clara, como se pode ver abaixo:

[...] as atuais taxas de aumento populacional não podem continuar. Já estão comprometendo a capacidade de muitos governos de fornecer educação, serviços médicos e segurança alimentar às pessoas, e até a sua capacidade de elevar padrões

2 O Clube de Roma é um grupo de pessoas ilustres que se reúnem para debater um vasto conjunto de assuntos relacionados a política, economia internacional e, sobretudo, meio ambiente. Foi criado em 1968, mas ficou muito conhecido a partir de 1972, ano da publicação do relatório contratado pelo grupo e denominado Limites do crescimento. 
de vida. Esta defasagem entre número de pessoas e recursos é ainda mais premente porque grande parte do aumento populacional se concentra em países de baixa renda, em regiões desfavorecidas do ponto de vista ecológico e em áreas de pobreza (CMMAD, 1991, p. 103).

As questões relacionadas ao crescimento da população foram novamente discutidas na segunda Conferência das Nações Unidas sobre de Meio Ambiente e Desenvolvimento, realizada em 1992, no Rio de Janeiro. A Agenda XXI, principal documento resultante dessa conferência, discute, entre outros assuntos, questões ligadas à dinâmica demográfica e sustentabilidade. Apesar de não citar a teoria malthusiana e incluir outros elementos na discussão, como, por exemplo, os padrões não sustentáveis de consumo, ela apresenta como proposta um dos argumentos malthusianos: o controle demográfico. No capítulo 5, no item 5.17, ao tratar dos objetivos do capítulo, diz:

Deve ter prosseguimento a total incorporação das preocupações com o controle demográfico aos processos de planejamento, formulação de políticas e tomadas de decisão no plano nacional. Deve ser considerada a possibilidade de se adotarem políticas e programas de controle demográfico que reconheçam plenamente os direitos da mulher (CMMAD, 1997, p. 51).

Outro argumento utilizado pelo campo hegemônico como pressuposto do desenvolvimento sustentável é a crítica à finitude dos recursos naturais, principalmente os atuais padrões de produção e consumo. Diferentemente das questões relacionadas à população e meio ambiente que já persistem há mais de dois séculos, essa é uma preocupação que surgiu na década de 1960-1970.

No final da década de 1960, o documento Limites para o Crescimento defendeu, numa perspectiva catastrófica, que o crescente consumo geral levaria a humanidade a um limite de crescimento e, possivelmente, a um colapso. Na década de 1990, essa preocupação foi retomada na Conferência das Nações Unidas sobre o Meio Ambiente e Desenvolvimento. A Agenda XXI, ao abordar o tema Mudança dos Padrões de Consumo, diz que "[...] as principais 
causas da deterioração interrupta do meio ambiental mundial são os padrões insustentáveis de consumo e produção, especialmente dos países industrializados" (CMMAD, 1997, p. 39). Reconhece ainda que, em determinadas partes do mundo, os padrões de consumo são muito altos e que existe um amplo seguimento da sociedade que não é atendido em suas necessidades básicas. É importante ressaltar que, apesar de o documento reconhecer a desigualdade no consumo entre países ricos e pobres, as alternativas recomendadas para o enfrentamento da problemática sugerem apenas mudanças comportamentais na forma de consumir e produzir. Quanto à forma de consumir, propõem que os governos devem estimular grupos de consumidores, indivíduos através da "[...] oferta de informações sobre as consequências das opções e comportamentos de consumo, de modo a estimular a demanda e o uso de produtos ambientalmente saudáveis" (CMMAD, 1997, p. 44). Quanto ao processo produtivo, a alternativa apresentada está na eficiência no uso da energia e dos recursos e ao desenvolvimento de tecnologias ambientalmente saudáveis. O item 4.18 diz que "[...] a redução do volume de energia e dos materiais utilizados por unidade na produção de bens e serviços pode contribuir simultaneamente para a mitigação da pressão ambiental e aumento da produtividade e competividade econômica e industrial" (CMMAD, 1997, p. 43).

Como foi visto, apesar de o documento reconhecer uma diferença nos padrões de consumo entre os países ricos e pobres, não apresenta, como já era esperado, as contradições presentes nesse processo. Não reconhece que o que leva toda essa problemática são as relações sociais que firmam entre os seres humanos a partir da maneira como se distribuem os meios de produção. Essa distribuição dos meios de produção é que determina um ingresso diferente ao meio ambiente, graus de interferências e de decisão sobre o uso do meio ambiente e a forma e o tipo de recursos a utilizar e consumir.

Por entenderem que a questão crucial em relação aos padrões de produção e consumo se relaciona à finitude dos recursos naturais, as alternativas apresentadas nos documentos oficiais, como a Agenda XXI, visam estimular novas formas de consumo. Nesse sentido, vêm sendo construídas propostas que consagram o 
mercado sem alterar o modo de produção capitalista, como é o caso do consumo verde ou sustentável/responsável/eficiente. A proposta é que as pessoas continuem consumindo, só que agora produtos ecologicamente corretos, saudáveis ao meio ambiente. Essa alternativa dentro dos marcos do mercado garante que o ciclo produção/consumo se reproduza sem alteração do modo de produção vigente.

Numa análise superficial, pode-se compreender que os argumentos apontados pela visão hegemônica, relacionada à população e ao meio ambiente, e os altos padrões de consumo estão ligados aos limites dos recursos naturais, levando ao entendimento de que existe uma contradição insuperável entre um mundo com recursos finitos e um crescimento infinito da produção. No entanto, a contradição entre os limites físicos e o desenvolvimento social é equivocada, uma vez que a sociedade nunca se defronta em seu conjunto com limites físicos, pois, como muito bem esclarece Foladori (2001a, p. 18), “[...] a sociedade humana antes de deparar com limites naturais ou físicos está frente a frente com as contradições sociais".

Para Foladori e Tommasino (2011), colocar que existem limites físicos para o desenvolvimento é uma forma de considerar os problemas ambientais como técnicos. Não resta dúvida de que existem problemas técnicos no relacionamento entre a sociedade e a natureza, mas estes estão subordinados a formas de produção e organização social. No entanto, para a visão hegemônica, a técnica é pensada fora de um marco de sistema de relações sociais ou modo de produção. Portanto, nessa visão, as tecnologias são neutras, e não resultado das relações sociais. É por isso que as alternativas apresentadas pela perspectiva conservadora em relação aos problemas ambientais vão privilegiar a técnica como solução. Além disso, "[...] o discernimento de escolha de uma técnica por parte do capital é a sua potencialidade de produção de mais-valia, mesmo quando se encontram à disposição melhores alternativas relativas ao uso social, ao consumo de energia e ao meio ambiente" (ANDRIOLI, 2008, p. 14).

Quando se recorre à tecnologia como única solução no enfrentamento dos problemas ambientais, finge-se não ser necessário 
alterar as relações sociais de produção da sociedade capitalista, o que dá origem a um pensamento mágico. Segundo Andrioli (2008), esse pensamento vem predominando nas discussões em relação às alternativas para as questões ambientais. Por exemplo, existe a crença de que o aumento da eficiência tecnológica pode permitir que a economia cresça exponencialmente, ao mesmo tempo em que reduz as emissões de carbono e outras formas de degradação ambiental. Isso significa ignorar que o aumento da eficiência é utilizado para ampliar a escala do sistema, reduzindo ou eliminando os eventuais ganhos de aumento de eficiência energética.

A perspectiva hegemônica considera, ou melhor, crê que a tecnologia é a solução para os problemas ambientais. Em relação aos padrões de produção e consumo, tanto as propostas oficiais, como Agenda XXI, quanto as propostas das organizações da sociedade civil, que comungam com essa perspectiva, são unânimes em apontar a tecnologia aliada a um trabalho educativo como o caminho para que se atinja a qualidade ambiental e o chamado desenvolvimento sustentável.

Analisando o conteúdo, as estratégias, as bases de ação do capítulo 4, Mudanças de padrões de consumo da Agenda XXI, entre outras recomendações, destacam-se: a) estímulo à difusão de tecnologias ambientalmente saudáveis já existentes; b) estímulo ao uso ambientalmente saudável de fontes de energia novas e renováveis, c) estímulo à reciclagem no nível dos processos industriais e do produto consumido; d) estímulo à redução do desperdício na embalagem dos produtos; e) conscientização dos consumidores acerca do impacto dos produtos sobre a saúde e meio ambiente, por meio de uma legislação que proteja o consumidor e dê uma rotulagem com indicações ecológicas; f) estímulo a determinados programas expressamente voltados para interesses do consumidor, como a reciclagem e sistemas de depósitos e restituição (CMMAD, 1997, p. 43).

Essas recomendações deixam claro que as mudanças propostas são atreladas aos mecanismos de mercado e se adaptam perfeitamente ao modelo econômico vigente. Tomando como exemplo a reciclagem, pode-se dizer que esta é uma condição importante para a conservação dos sistemas materialmente limitados, porém, 
realizada isoladamente, não é condição suficiente, pois visa apenas desobstruir o gargalo, adaptando ao modelo econômico atual, através de uma visão utilitarista de curto prazo, mantendo a associação entre consumo e qualidade de vida. Ademais, a ênfase na reciclagem acontece porque não entra em conflito com o capital.

Além desses pressupostos, atualmente uma das alternativas apresentadas pelo capital para se atingir o desenvolvimento sustentável é a economia verde. O termo economia verde surgiu na conjuntura da Rio-92, mas somente agora tem sido retomado. A economia verde foca as mudanças climáticas globais e discute temas como economia de baixo carbono, eficiência energética e energia renovável. A economia verde vem sendo considerada pelo capital como uma excelente oportunidade de criação de novos negócios para as empresas e um novo fluxo de recursos financeiros.

O Relatório Rumo à economia verde: caminhos para o desenvolvimento sustentável e erradicação da pobreza do Programa das Nações Unidas para o Meio Ambiente (PNUMA) define economia verde "[...] como uma economia que resulta em melhoria do bem-estar da humanidade e igualdade social, ao mesmo tempo em que reduz significadamente riscos ambientais e escassez ecológica" (PNUMA, 2011, p. 1). É uma economia apoiada em três estratégias principais: i) redução das emissões de carbono; ii) maior eficiência energética; iii) prevenção da biodiversidade e dos serviços ecossistêmicos.

Para Young (2011), o conceito de economia verde proposto pelo PNUMA sugere que a dinamização da economia deve acontecer através da expansão de setores de baixo impacto ambiental, do incentivo de ações como agricultura sustentável, da gestão de resíduos, transportes verdes, tecnologias limpas, energias renováveis, prédios verdes, manejo florestal e pagamento por serviços ambientais. Essa proposta de reconfiguração das atividades econômicas tem como meta oferecer, ao mesmo tempo, o melhor retorno sobre os investimentos em capital natural, humano e econômico, reduzir a pressão sobre o meio ambiente e contribuir para a equidade social.

De acordo com o documento do PNUMA (2011), além de dinamizar a economia com o investimento em setores de baixo impacto ambiental, na economia verde os empregos também serão verdes. 
Empregos verdes são "[...] aqueles que contribuem para preservar ou restaurar os ecossistemas e - requisito essencial - têm características de valorização da pessoa e do trabalho humano: são empregos formais e com remuneração digna" (ALMEIDA, 2009, p. 20). Ressalte-se, ainda, que os empregos verdes estarão em muitas atividades produtivas, as mais específicas, mas não as únicas, como é o caso: da gestão de biodiversidade e dos ecossistemas; dos processos de transformação de alta eficiência no uso da energia, água e materiais; da descarbonização da economia; e dos processos destinados a evitar toda a forma de resíduo ou poluição.

Numa visão superficial, pode parecer que a proposta da economia verde é o instrumento pelo qual os problemas ambientais e sociais serão solucionados. No entanto, numa perspectiva crítica e de totalidade, é possível dizer que a economia verde é uma reapresentação em nova embalagem das estratégias que vêm sendo defendidas pelo capital desde a década de 1990, só que agora atualizada por uma leitura conjuntural mais pertinente com a realidade contemporânea, em que a ideia mais abrangente de Economia parece trazer benefício de um olhar mais integrador do que no âmbito das empresas.

A tentativa de a economia verde ter um olhar mais integrador e aparentemente crítico está presente em todo o documento. Logo na introdução, o texto diz:

[...] este recente impulso para um conceito de economia verde, sem dúvida foi ajudado pela grande desilusão em relação ao paradigma econômico predominante; uma sensação de fadiga emanando das várias crises simultâneas e falhas de mercado vividas durante a primeira década do novo milênio, incluindo principalmente, a crise financeira e econômica de 2008 (PNUMA, 2011, p. 1).

Essa preocupação, que parece ser para além dos aspectos econômicos, ensaia até uma crítica ao uso inadequado do capital e dos mercados, como se pode ver:

[...] as políticas existentes e os incentivos de mercado contribuíram para o problema de uso inadequado de capital, pois eles permitem que as empresas acumulem externalidades ambientais e sociais importantes, em sua maioria sem explicações ou verificações. 
Os mercados livres não têm como função resolver os problemas sociais, portanto, existe uma necessidade por melhores políticas públicas, incluindo atribuição de preços e medidas regulamentares, para mudar esses incentivos prejudiciais do mercado que estão por trás do uso inadequado de capital e ignoram as externalidades ambientais e sociais (PNUMA, 2011, p. 1).

Uma economia verde é primordial para a diminuição da pobreza. A pobreza contínua é a forma mais visível de desigualdade social, que está relacionada ao acesso desigual à educação, saúde, disponibilidade de crédito, oportunidades de renda e garantia de direitos de propriedades. Uma característica importante de uma economia verde é que ela procura gerar diversas oportunidades para o desenvolvimento econômico e diminuição da pobreza sem liquidar com os bens naturais de um país (PNUMA, 2011, p. 9).

No entanto, apesar de o documento tentar esse olhar mais integrador, deixa claro, ainda na introdução, que o compromisso da economia verde é com o capital:

Talvez o mito mais difundido seja o de que há uma troca inevitável entre sustentabilidade ambiental e progresso econômico. Agora há evidência substancial de que o "esverdeamento" de economias não inibe a criação de riqueza ou oportunidades de emprego, e que há muitos setores verdes que apresentam oportunidades significativas de investimento e crescimento relacionado de riqueza e empregos (PNUMA, 2011, p. 3).

São vários os exemplos no documento que demonstram que a economia verde apresenta "[...] maiores oportunidades econômicas [...]”. Em relação à substituição dos combustíveis fósseis por energias renováveis e tecnologias de baixa emissão de carbono, diz:

O enverdecimento da energia requer a substituição dos investimentos em fontes de energia intensivas em carbono por investimentos de energia limpa, bem como aprimoramentos de eficiência. [...] A partir de meados de 2002 até meados de 2009, o total de investimentos em energias renováveis exibiu uma taxa de crescimento anual composta de $33 \%$. Apesar da recessão mundial, esse setor está em rá- 
pida expansão. Para 2010, espera-se que novos investimentos em energia limpa atinja um recorde de US\$ 180 a 200 bilhões, de US\$ 162 bilhões em $2009 \mathrm{e}$ US\$ 173 bilhões em 2008 (PNUMA, 2011, p. 14).

Para Sawyer (2011, p. 36), a proposta de economia verde, que aparentemente se apresenta no lugar da proposta de desenvolvimento sustentável - este sendo considerado um termo desgastado ou esvaziado (FASE, 2011) -, "[...] merece uma série de cuidados". Para o referido autor, existem interesses econômicos por trás de novas propostas. Assim, mudar o substantivo desenvolvimento, que em tese possui pelo menos as dimensões social e ambiental (se não outras), para economia significa dar ênfase a apenas uma das dimensões. Tende a dar valor aos economistas e seus instrumentos econômicos no lugar da regulação estatal, que é considerada como "[...] comando e controle [...]". Prova disso é que, nessa proposta, natureza torna-se "[...] capital natural [...]", com ênfase nos instrumentos econômicos, como o pagamento de serviços ambientais.

Sawyer (2011) chama a atenção para o fato de que o discurso da economia verde está bem articulado em marcos como capital natural, redução da pobreza, baixo carbono, eficiência energética, inovação, agenda verde, governança global, características aparentemente atraentes. No entanto, todos esses conceitos também podem ser:

[...] jeitinhos engenhosos para substituir ou relegar a soberania, a equidade, a natureza, as funções ecológicas, ou uso sustentável, os direitos fundamentais (humanos e cidadania) e a redução de emissões (inclusive sequestrando carbono) entre outros valores importantes (SAWYER, 2011, p. 39).

Não resta dúvida de que, diante da atual crise do capital e ambiental, são necessárias mudanças profundas no atual modelo econômico, que pautem novas relações com a natureza. No entanto, as propostas sugeridas pelo PNUMA preconizam apenas esverdear o capitalismo. É nesse sentido que se pode afirmar, concordando com Avignon e Caruso (2011, p. 25), que "[...] pintar a economia neoclássica de verde não será a solução”. 
Um exemplo, citado pelos referidos autores, que demonstra a fragilidade da proposta de esverdeamento da economia neoclássica se refere à valoração da biodiversidade. Esta, como um bem público, não é valorada na economia neoclássica corretamente, assim como os serviços ambientais. A saída, portanto, proposta pela economia verde, é estimar adequadamente o valor econômico desses serviços ambientais, os quais poderiam contribuir para o bem-estar humano e o sustento de famílias, além de ser fonte de novos empregos. Essa é uma das dimensões que sustentariam a transição para uma economia verde, estimulando a mudança dos antigos indicadores econômicos e levando-os a estimar a perda de capital natural como componente negativo e não positivo das contas nacionais.

Para dar suporte à precificação e valoração dos recursos naturais, foi elaborado, a pedido do G8+5 em 2007, um estudo denominado A economia dos Ecossistemas e da Biodiversidade (TEEB), com o objetivo de dar o processo de valoração dos serviços ambientais e permitir uma simplificação dos valores da biodiversidade, simplificação necessária para ser apropriada pelo mercado produtivo e financeiro.

O TEEB divide os valores econômicos da biodiversidade em valores de uso e valores de não uso. Os valores de uso podem ser de uso direto (alimento, madeira, medicamentos, beleza cênica, turismo), de uso indireto (regulação do clima, armazenamento de carbono, manutenção dos ciclos hidrológicos) e valores de opção (deixar a opção ou expectativa de uso futuro da biodiversidade, como para fins medicinais). Já os valores de não uso são atribuídos por um agente, independentemente de ele mesmo se beneficiar do uso: são os valores de legado e os valores de existência. Valor de legado é aquele atribuído a algo para que seja conservado para gerações futuras (habitats, espécies ameaçadas, etc.), enquanto os valores de existência são aqueles atribuídos independentemente do uso, como a importância de se proteger uma espécie em seu habitat, como o urso polar (PACKER, 2011).

A autora ressalta que todos esses valores, assim como os culturais, religiosos e sociais, dependem de quem é o sujeito que valora. As 
comunidades locais que detêm inúmeras formas não catalogadas de uso, manejo e técnicas sociais ligadas à conservação e uso sustentável da biodiversidade, podem valorar os componentes da biodiversidade de forma diferente do estabelecido pelo TEEB. A metodologia proposta pelo TEEB leva à definição de poucas variáveis ou indicadores da diversidade, já que um preço imposto pelo custo de oportunidade para a cadeia produtiva é que irá expressar o valor do serviço ambiental. Para determinar esse custo de oportunidade, o TEEB apresenta um cenário comparativo dos custos na manutenção da biodiversidade em relação aos custos gerados para a empresa com a realização dos danos ambientais. O estudo determina várias formas de cálculo, mas todas elas partem do pressuposto da comparação entre ter um projeto de Pagamento de Serviços Ambientais³ (PSA) e os custos de não tê-los. O PSA água, por exemplo,

[...] apresenta a conta dos custos de investimentos em pagamentos por "serviços" ambientais aos agricultores para preservarem as nascentes e cursos d'água, em comparação aos custos com estações de tratamento. Nesse exemplo, o preço do PSA seria calculado pelo valor do tratamento da água (PA(KER, 2011, p. 6).

Portanto, através das necessidades do capital e da cadeia de produção é que serão estipulados os valores pelos serviços prestados pela biodiversidade e ecossistemas. A autora ainda alerta que

[...] se valer a pena financeiramente pagar para manter a floresta de pé como "valor de opção" (especulação da terra e dos recursos), para fazer reserva de mercado para o desenvolvimento futuro de medicamentos e cosméticos, o mercado favorece as florestas. Caso as commodities agrícolas se valorizem, não há motivo para conservação (PACKER, 2011, p. 6).

\footnotetext{
3 Serviços ambientais são as atividades, produtos e processos prestados de forma natural e gratuita pelos ecossistemas para a manutenção de condições ambientais adequadas para a vida no Planeta. Os "serviços ambientais" prestados pela natureza fornecem produtos como alimentos, remédios naturais, fibras, combustíveis, água, oxigênio etc. e garantem o bom funcionamento dos processos naturais, como o controle do clima, a purificação da água, os ciclos de chuva, o equilíbrio climático, o oxigênio para respirarmos, a fertilidade do solo e a reciclagem dos nutrientes necessários, por exemplo, para a agricultura (PACKER, 2011).
} 
Em relação à valoração da biodiversidade através do (PSA), May (2011) explica que um dos principais pensadores sobre o assunto, Wunder, classifica os PSA como qualquer transação que envolve pelo menos um comprador, um vendedor e um serviço ambiental no pagamento entre as partes. Sendo assim, existirão condições para uma negociação caso o custo de prover o serviço somado aos custos de transação em realizar o negócio for menor do que os benefícios socioambientais obtidos conjuntamente pelos compradores (sejam locais ou globais).

Para May (2011), a dificuldade nessa transação é que as benfeitorias dos PSA atendem a muitos - alguns pegando carona no empenho dos outros -, incitando, assim, pouco incentivo em contribuir. Por isso, quando as informações são assimétricas, os custos de transação tendem a ser novamente altos. Além disso, existem problemas de insegurança nos contratos, como, por exemplo, o agente comprador é o único responsável pelo cumprimento do que é estabelecido com o vendedor dos créditos de carbono com reduções de emissões. Com isso, se acontecer algum problema nesse processo, é responsabilidade apenas do comprador buscar uma fonte alternativa de carbono ou securitizar para cumprir suas obrigações de redução. Por tudo isso, o autor conclui que "[...] existem abundantes falhas no mercado para negociações desse teor" (MAY, 2011, p.174)4.

Essas e outras críticas também são compartilhadas por Packer (2011). Para a autora, a valoração da biodiversidade através do PSA é um mecanismo criado para fomentar a criação de um novo mercado, que tem como mercadoria os processos e produtos fornecidos pela natureza, como a purificação da água, do ar, a geração de nutrientes do solo para a agricultura, a polinização e o fornecimento de insumos para a biotecnologia. Esse mecanismo propõe ser um instrumento de incentivo ao agente econômico para a conservação ambiental, pelo zelo e manejo sustentável do solo, da flores-

\footnotetext{
4 Apesar dessas críticas, May (2011) entende que os instrumentos de mercado devem assumir um papel importante na transição para uma economia verde. Para ele, tal papel deverá ser mediado por uma regulação definidora de critérios de acesso e controle sobre os recursos naturais, refletindo-se em limites biofísicos amparados nas ciências e ampla e prévia consulta às populações que dependem de tais recursos para seu sustento.
} 
ta e da água. É uma proposta para tentar solucionar os problemas ambientais dentro da lógica do mercado, sem questionar as estruturas do capitalismo.

É nesse contexto que se pode afirmar que somente o esverdeamento da economia não consegue implementar as mudanças necessárias que atual crise ambiental exige. A Economia Verde é uma estratégia pensada dentro da lógica do mercado fundado em business verde, instrumentos de mercado e precificação dos recursos naturais e apropriação do bem comum. Além disso, concordando com o professor Sawyer (2011), a economia verde é uma proposta que tende a se tornar uma lavagem verde cosmética, pois pode se resumir a atividades ou projetos verdes atualmente na moda, tais como painéis fotovoltaicos, moinhos eólicos, parques nacionais remotos, pontos de reciclagem de lixo, hortas orgânicas e pousadas ecoturísticas na selva. Além disso, a economia verde é uma "[...] reciclagem das clássicas formas de funcionamento do capitalismo, de seus modos de acumulação e expropriação, [e] constitui-se em estelionato grave de consequências profundas" (FASE, 2011, p. 2). É uma proposta que visa dar novo fôlego com um único objetivo: contribuir para a acumulação e reprodução do capital.

\section{CONSIDERAÇÕES FINAIS}

Como foi visto, as propostas produzidas pelos órgãos oficiais que preconizam o desenvolvimento sustentável, como a Agenda XXI e a Economia Verde, evidenciam o compromisso da corrente hegemônica com a conservação da ordem política, social e econômica vigente. Essas alternativas são pensadas dentro da lógica do mercado e se conectam perfeitamente, portanto, ao fluxo da história das classes dominantes. Um exemplo que confirma esse compromisso é o Protocolo de Quioto. Ele prevê, dentro dos marcos atuais, que a redução das emissões de carbono na atmosfera seja estabelecida dentro de um limite médio imposto globalmente. As nações ricas ganham o direito de poluir, aumentando a produção industrial e compensando suas emissões de carbono através de um mecanismo de mercado, ou seja, compram as cotas dos países pobres possuidores de baixa atividade industrial para manterem o crescimento econômico. É o velho princípio: eu pago, eu poluo. 
Além disso, pode-se dizer que as alternativas defendidas pelo campo hegemônico preconizam a capacidade de alcançar o desenvolvimento sustentável dentro da ordem do capital. Entende-se, nesse contexto, que é possível reformar o capitalismo, atingir um capitalismo mais verde, mais respeitoso com o meio ambiente, com propostas que se restringem a processos de produção, tecnologia, reciclagem, eficiência energética, consumo responsável etc., despolitizando o debate. É com base nisso que se pode dizer que essa visão possui uma crítica limitada, pois traz ações remediadoras, ajustes nos efeitos e consequências. Nesse sentido, Löwy e Boff (2008, p. 80) dizem: “[...] soluções que aceitam as regras do jogo capitalista, que aceitam a lógica de expansão infinita do capital, não são soluções, pois são incapazes de responder os desafios dessa crise". Essas ações reformistas, remediadoras não são surpresa, e nem poderia ser de outra maneira, pois enfrentar a destruição ambiental em suas causas exige a adoção de estratégias reprodutivas que, mais cedo ou mais tarde, enfraqueceriam inteiramente a viabilidade do sistema do capital.

Para finalizar, é importante ressaltar que o campo conservador tem como denominador comum a despolitização da questão ambiental e, no entender de Coggiola (2010), com esse pensamento fala-se do meio ambiente e do planeta como se fala do tratamento de um enfermo, que se tem que curar, mas em nenhum caso descrevem que vírus provoca a enfermidade. Escondem-se as forças que destroem o meio ambiente - e também os milhares de milhões de marginalizados, que sofrem as principais consequências.

\section{REFERÊNCIAS}

ACSERALD, H. Justiça Ambiental: ação coletiva e estratégias argumentativas. In: ACSERALD, H.; HERCULANO S.; PÁDUA, J. A. (Org.). Justiça ambiental e cidadania. Rio de Janeiro: Relume Dumará, 2001.

ALMEIDA, F. Experiências empresariais em sustentabilidade: avanços, dificuldades e motivação de gestores e empresas. Rio de Janeiro: Elsevier, 2009.

ANDRIOLI, A. I. A atualidade de Marx para o debate sobre a tecnologia e meio ambiente. Crítica Marxista, n. 27, p. 11-25, 2008. 
AVIGNON, A. d'; CARUSO, L. A. C. O caráter necessariamente sistêmico da transição rumo à economia verde. Política Ambiental, economia verde: desafios e oportunidades. Belo Horizonte: Conservação Internacional. n. 8, p. 24-35, jun. 2011. Disponível em: <http://www.conservacao.org.br/publicacoes/files/poltica_ambiental_08_portugues.pdf. Acesso em: 10 out. 2011.

CMMAD. Nosso futuro comum. Rio de Janeiro: Fundação Carlos Chagas, 1991.

. Agenda XXI. Brasília: Senado Federal, 1997.

COGGIOLA, O. Crise ecológica, luta de classes. In: SILVA, M. G. da. (Org.). Marxismo e natureza: ecologia, história e política. Pará de Minas: Virtual Books, 2010.

FASE. Rio+20: resistir ao ambientalismo de mercado e fortalecer os direitos e a justiça ambiental. Rio de Janeiro: Federação de órgãos para assistência social e educacional, 2011. Disponível em: <http:// fase.org.br/v2/pagina.php?id=3484>. Acesso em: 11 out. 2011 FOLADORI, G.; TOMMASINO, H. A solução técnica para os problemas ambientais. Contra Corrente, ano 3, n. 5, p.27-28, 2011.

FOLADORI, G. Limites do desenvolvimento sustentável. Campinas: Unicamp, 2001a.

FOSTER. A ecologia de Marx. Rio de Janeiro: Civilização Brasileira, 2005. LOUREIRO, C. F. B. O movimento ambientalista e o pensamento crítico: uma abordagem política. 2. ed. Rio de Janeiro: Quartet, 2006. LÖWY, M.; BOFF, L. A natureza e o meio ambiente: limites do planeta. In: MENEGAT, M.; BEHRING, E. R.; FONTES, V. (Org.). Dilemas da humanidade. Rio de Janeiro: Contraponto, 2008.

LUKÁCS, G. Prolegômenos para uma ontologia do ser social. São Paulo: Boitempo, 2010.

MALTHUS, T. R. Textos de Malthus. In: SZMRECSÁNYI, T. (Org.); FERNANDES, F. (Coord.). Malthus: economia. São Paulo: Ática, 1982. MARX, K. Grundrisse. São Paulo: Boitempo, 2011.

MARX, K. O capital: crítica da economia política, Livro Primeiro, o processo de produção do capital v. II. 12. ed. Rio de Janeiro: Bertrand, 1983. 
MARX, K. Crítica ao programa de Gotha. In: MARX, K.; ENGELS, F. Obras escolhidas. São Paulo: Alfa-Ômega, 1981.

MAY, P. H. Mecanismos de um mercado para uma economia verde. Política Ambiental. Economia verde: desafios e oportunidades. Belo Horizonte: Conservação Internacional. n. 8, p. 170-178, jun. 2011. Disponível: <www.conservacao.org.br/publicacoes/files/poltica_ambiental_08_portugues.pdf >. Acesso em: 10 out. 2011.

MÉSZÁROS, I. Estrutura social e formas de consciência Il: a dialética da estrutura e da história. São Paulo: Boitempo, 2011.

. A teoria da alienação em Marx. São Paulo: Boitempo, 2006.

. Para além do capital. São Paulo: Boitempo, 2002.

PACKER, L. Pagamentos por serviços ambientais e flexibilização do Código Florestal: para um capitalismo "verde". Curitiba: Terra de Direitos, 2011. Disponível em: <http://terradedireitos.org.br/biblioteca/pagamento-por-servicos-ambientais-e-flexibilizacao-do-codigo-florestal-para-um-capitalismo-verde/>. Acesso em: 02 set. 2011.

PINTO, V. P. dos S. Ecodesenvolvimento, desenvolvimento sustentável e as diferentes propostas de sustentabilidade para a Amazônia brasileira. In: ZACARIAS, R.; PINTO, V. P. dos S. (Org.). Educação ambiental em perspectiva. Juiz de Fora: FEME, 2002.

PNUMA. Rumo à economia verde: caminhos para o desenvolvimento sustentável e a erradicação da pobreza, síntese para tomadores de decisão, 2011. Disponível em: <http://www.unep.org/greeneconomy >. Acesso em: 28 set. 2011.

RODRIGUES, F. X. F. População e meio ambiente: uma análise das abordagens malthusiana, marxiana e cornucopiana. 2011. Disponível em: <http://www.cidehus.uevora.pt/investigacao/progcien/ linv/13/ics/capitulos/autores/textos/demografia/malthus_marx_boserup_txtfx.htm>. Acesso em: jul. 2011.

SAWYER, D. Economia verde e/ou desenvolvimento sustentável. Política Ambiental. Economia verde: desafios e oportunidades. Belo Horizonte: Conservação Internacional, n. 8, p. 36-42, jun. 2011. Disponível em: <http:// http://www.conservacao.org/publicacoes/files/politica_ambiental_08_portugues.pdf >. Acesso em: 15 out. 2011. 
YOUNG, C. E. F. Potencial de crescimento da economia verde no Brasil. Política Ambiental, Belo Horizonte, n. 8, p. 88-97, jun. 2011. Disponível em: <http://www.conservacao.org/publicacoes/files/ P\%E1ginas\%20de\%20PoliticaAmbientalo8young.pdf >. Acesso em: 15 out. 2011. 